\title{
FIOS E ENTEADOS: REENCENAÇÕES FILIAIS NO ROMANCE MACHADIANO
}

\section{DIANA DUARTE FERREIRA}

Universidade Nova de Lisboa

Lisboa, Portugal

Resumo: Embora os problemas de geração e filiação sejam universais, Edward Said notou como essa tópica é particularmente recorrente no modernismo. O mesmo se pode verificar no conjunto romanesco de Machado de Assis: a incidência crítica das dificuldades filiativas, desde o plano da narrativa (narrador, enredo, personagens) ao plano do livro (escritor, publicação, crítica), pervagando o plano do romance (o problema do autor suposto e da assinatura), é extraordinária. Este artigo procura demonstrar, a partir das metáforas autorais platónicas e por meio de exemplos concretos, desde Ressurreição ao Memorial de Aires, como a tópica da filiação problemática é constitutiva do romance machadiano.

Palavras-chave: génese; adoção; legado; romance; autoria.

\section{YARNS AND STEPCHILDREN: FILIAL RE-ENACTEMENTS IN MACHADIAN} NOVEL

Abstract: Although the problems of generation and filiation are universal, Edward Said drew attention to how this topic is particularly recurrent in modernism. The same can be said about Machado de Assis' novel ensemble: the critical incidence of affiliative difficulties on all levels - narrative (narrator, plot, characters), book (author, publication, critic), and novel (problem of the supposed author and signature) - is remarkable. This article seeks to demonstrate, through Platonic authorial metaphors and concrete examples - from Ressurreição to Memorial de Aires - how the topic of challenging filiation is constitutive of Machado's novel.

Keywords: genesis; adoption; legacy; novel; authorship. 
Childless couples, orphaned children, aborted childbirths, and unregenerately celibate men and women populate the world of high modernism with remarkable insistence, all of them suggesting the difficulties of filiation.

Edward W. Said, The World, the Text, and the Critic

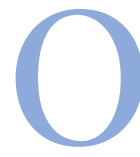

decepar da filiação é a primeira face do que Said descreve como um padrão ternário. As pontas soltas criam a necessidade de laços afiliativos que já não dependem da procriação, mas do entretecer de afinidades. Esse entretecer dá forma a um novo sistema que eventualmente reproduz estruturas idênticas às da família que não se pôde ter ou se recusou. Said concentra-se nessa terceira face do padrão, descrita como instância da passagem da natureza à cultura, para questionar as hierarquias culturais e canónicas criadas pela afiliação, nomeadamente no que concerne à crítica literária (SAID, 1983, p. 16-20).

Os problemas de filiação não são, porém, exclusivamente modernos ou modernistas. A criatura criadora constitui um problema em atualização constante. A sua prolífica reencenação é indissociável da transição histórica determinada por fenómenos como a disseminação da escrita e as revoluções liberais. No que diz respeito à filiação, poderíamos fazer um esboço muito esquemático isolando por alto o que permaneceu e mudou entre as diferentes épocas. Se olharmos para a consanguinidade da alta nobreza (que data pelo menos do antigo Egipto) e para a abstinência do clero (imposta e violada) como rodas metonímicas de uma engrenagem que serve à manutenção do poder e ao mesmo tempo o ameaça com os detritos produzidos pelo seu funcionamento, chegamos a uma formulação simples e útil: os problemas de sucessão geram uma sucessão de problemas, sociais e individuais.

A máquina patriarcal do ocidente tornou-se mais sofisticada na transição para a modernidade, mais independente de linhagens biológicas e espirituais: a soberania deixou de ser ameaçada pela morte de algum rei sem herdeiros, pecado e crime tornaram-se coisas distintas, o indivíduo ganhou terreno. A noção de continuidade dinástica converteu-se em metáfora afiliativa, preservando, todavia, o teor oligárquico e a preponderância do domínio e da autoridade que se deseja manter além da vida. Os romances machadianos são para aqui chamados porque se situam - e nos situam - no limbo histórico entre regimes políticos e sociais, culturais e artísticos. E, claro, por serem exemplares da moderna reencenação do paradoxo humano performado sob as 
perspetivas da criatura e do criador. Desde as Memórias póstumas de Brás Cubas ao Memorial de Aires observam-se várias instâncias desse drama.

A "derradeira negativa" com que Brás Cubas remata as Memórias póstumas corresponde ao "pequeno saldo" com que se acha depois de morto: "Não tive filhos, não transmiti a nenhuma criatura o legado da nossa miséria" (ASSIS, 2013, p. 314). Contas feitas, o saldo consiste no legado do pai. Podemos considerar que a educação adulatória, a abastança familiar e o desejo de nomeada que são transmitidos pelo pai constituem um obstáculo conjuntural a que o filho concretize, durante a vida, uma vocação autoral todo o tempo latente. Por outro lado, são esses fatores que delineiam a experiência de vida sem a qual Brás Cubas não se teria constituído autor postumamente.

Dom Casmurro rejeita o filho porque lhe atribui outro pai. Não tendo como se certificar, a dúvida acompanha-o. É um bom pretexto para notarmos a gradação entre dúvida e suspeita, dado que a suspeita da traição de Capitu se sobrepõe absolutamente à dúvida que suspenderia o juízo de Bentinho, e com ele o aniquilamento da própria descendência. É interessante observar que, instaurada a suspeita, a hipótese afiliativa nunca se apresenta ao protagonista como alternativa. Amor, compaixão e afinidade para com a criança só se manifestam teatralmente, para fazer face aos olhares e opiniões de outras pessoas, inclusive a do próprio filho Ezequiel. Há aí uma tensão entre o que Bentinho tolera que as pessoas reparem: não o podem ver a abandonar completamente o filho, mas também não podem continuar a ver o filho sob o risco de, percebendo as parecenças de Ezequiel e Escobar, olharem para Bentinho como um homem enganado pela esposa e pelo melhor amigo. A pressão da sociedade à qual Bentinho se sente afiliado, ainda que lhe dedique certa altivez, é internalizada e, sobrepondo-se aos laços filiativos, exteriorizada a ponto de o levar a exilar na Europa a família nuclear. Até que, sobrevivendo à esposa e ao filho, e perante a ausência de um legado humano, cria um sucedâneo narrativo que não deixa de perpetuar a própria recusa de paternidade.

O último capítulo de Quincas Borba devolve o leitor à indeterminação do título: "Mas, vendo a morte do cão narrada em capítulo especial, é provável que me perguntes se ele, se o seu defunto homônimo é que dá o título ao livro, e por que antes um que outro, - questão prenhe de questões, que nos levariam longe..." (ASSIS, 2012, p. 344). Por que não ambos? No legado do autor do Humanitismo não se incluía a obra - Brás Cubas conta, ainda nas Memórias póstumas, que o amigo "queimara o manuscrito todo e ia recomeçá-lo" (ASSIS, 2013, p. 312). Em Quincas Borba o narrador não faz, todavia, menção à 
destruição do manuscrito. Examinemos um conjunto de eventos que antecede a morte do filósofo:

a) Sabemos que Quincas Borba está perto de expirar e que o interesse e desvelo de Rubião para com o enfermo é de índole bem mais materialista do que filosófica. Abandona o magistério para cuidar do doente; em conversa com o médico afirma: "para ele, morrer é negócio fácil. Nunca leu um livro que ele escreveu, há anos, não sei que negócio de filosofia..." (ASSIS, 2012, p. 51).

b) Quincas Borba desvaloriza a morte e a extinção, sua e alheia; tenta transmitir oralmente a Rubião os princípios filosóficos de Humanitas com o episódio da morte bárbara da avó. Rubião até "escutava, com a alma nos olhos, sinceramente desejoso de entender" (ASSIS, 2012, p. 55), mas não conseguiu nem suspeitou que tais princípios velavam o "grãozinho de sandice" (ASSIS, 2012, p. 50). Pelo contrário, "perguntava a si mesmo como é que um homem, que ia morrer dali a dias, podia tratar tão galantemente aqueles negócios" (ASSIS, 2012, p. 57).

c) Quincas Borba tem a noção de que Rubião não consegue entender os princípios da sua filosofia. Ainda assim, como crê que "o Humanitismo é o remate das coisas" e que ele, seu autor, é "o maior homem do mundo", concede que Rubião possa vir a entender "aos poucos". Recruta-o como "discípulo" (ASSIS, 2012, p. 55).

d) No dia seguinte, Quincas Borba acorda resolvido a ir passar um mês no Rio de Janeiro. "Vou a alguns negócios pessoais, concluiu o enfermo, e levo, além disso, um plano tão sublime, que nem mesmo você poderá entendê-lo" (ASSIS, 2012, p. 58). Passada uma semana, a ideia da viagem persiste. Antes de partir, Quincas Borba toma a iniciativa de fazer o testamento.

Em Quincas Borba não há outra referência ao livro filosófico de Quincas Borba senão a menção de Rubião ao médico, o qual não o poderia ter lido porque nunca havia sido publicado - como sabemos pelas Memórias póstumas, o filósofo "aperfeiçoava de ano em ano" (ASSIS, 2013, p. 292) os "quatro volumes manuscritos, de cem páginas cada um, com letra miúda e citações latinas" (ASSIS, 2013, p. 249). Enquanto isso, ia difundindo os seus ensinamentos de forma exclusivamente oral. Podemos conjeturar que o "plano tão sublime" que Quincas Borba referiu a Rubião passava pela destruição do manuscrito na convicção de que a obra sobreviveria graças aos seus discípulos, a ela afiliados ao ponto de a continuarem a transmitir 
oralmente e, eventualmente, por escrito. Como aconteceu com Sócrates e Jesus, indivíduos afamados e publicados pelos seguidores.

Sem herdeiros biológicos, Quincas Borba fez de Rubião "herdeiro universal" - com a cláusula obrigatória de que passasse a cuidar do cão. E "impunha-lhe a condição, quando morresse o cachorro, de lhe dar sepultura decente [...] e mais desenterraria os ossos do dito cachorro [...] e os recolheria a uma urna de madeira preciosa para depositá-los no lugar mais honrado da casa" (ASSIS, 2012, p. 66-67). O cão, que afinal nada pode dizer, é o sucedâneo (ou afilhado) da obra destruída: "Porque a imortalidade é o meu lote ou o meu dote, ou como melhor nome haja. Viverei perpetuamente no meu grande livro. Os que, porém, não souberem ler, chamarão Quincas Borba ao cachorro" (ASSIS, 2012, p. 52). É o que afirma o filósofo em vésperas de destruir a obra. Rubião acabou perdendo todos os bens e, como se a sandice fizesse parte do legado, enlouqueceu convencendo-se que era Napoleão (recordo que as últimas palavras do desgraçado, feitas bordão incompreensível para os ajuizados, foram as do mestre: "Ao vencedor, as batatas!") (ASSIS, 2012, p. 343). E morreu antes do cão. A última cláusula do testamento ficava assim por cumprir. Quincas Borba é autor sem obra e cão sem dono: criaturas adotadas e apropriadas pelo autor do livro que lhes recolhe as ossadas.

Igualmente adotadas por quem pôde transformá-las em livro são as narrativas órfãs de Esaú e Jacó e do Memorial de Aires. O Conselheiro Aires, tendo cunhado no Memoriala expressão "orfandade às avessas" (ASSIS, 2003, p. 176) para ilustrar o drama, análogo ao seu, dos velhos que se veem sem ter a quem legar, deixa a obra à mercê da apropriação e torna-se um pai póstumo, mas truncado. É altura de esclarecer que a aparente confusão entre pais e autores, filhos e textos, se deve à força alegórica da filiação sobre a literatura e a autoria em geral. No Fedro de Platão há vários exemplos disso mesmo. Além do antropomorfismo do discurso, "que deve ser construído como um organismo vivo [...] com tronco e membros" (PLATÃO, 2009, 264c, p. 96), as óbvias relações de parentesco: o inventor da escrita é "pai da escrita" (PLATÃo, 2009, 274e, p. 120), o discurso vivo e animado é "irmão legítimo" (PLATÃO, 2009, 276a, p. 122) do discurso escrito, só determinados discursos se devem considerar "filhos legítimos" (PLATÃO, 2009, 278a, p. 127), e apenas esses são "não improdutivos mas possuidores de gérmen" (PLATÃO, 2009, 277a, p. 125). Oral ou escrito - mesmo porque Sócrates critica a escrita e logo a seguir usa-a como metáfora do efeito que o discurso vivo e animado exerce sobre a alma de quem o ouve - o discurso é uma criatura que, infértil ou produtiva, de algum modo espelha o criador e a própria criação. 
No que diz respeito à autoria, temos dois exemplos de criadores de discursos pautados por problemas filiais. Brás Cubas é o filho que através do romance aniquila o pai conservando-lhe o legado. ${ }^{1}$ Bentinho acaba por se dedicar à escrita depois de aniquilar o filho por crer que ele conservava o legado de outro homem. Quincas Borba e Aires também não têm herdeiros diretos e também representam autorias diametralmente opostas, mas os respetivos livros brindam-nos com a sucessão afiliativa: o primeiro destrói a obra cuja narrativa é reconstruída pela apropriação, o segundo conserva as narrativas que a apropriação desfaz para converter em obra. E se as diversas orfandades às avessas impressionam, as dificuldades afiliativas com que os protagonistas dos cinco romances se debatem não são menos são dignas de nota. À sua maneira, todos têm dificuldade em desempenhar o papel que as contingências lhes atribuem no teatro social. A seu modo, volto a frisar, nunca chegam a pertencer à sociedade da qual também não se conseguem ou querem desvincular.

A persistente alternância entre as tematizações machadianas da filiação e da afiliação recria, no debate entre natureza e cultura, privado e público, as forças em colisão ao longo da transição entre romantismo e modernismo. ${ }^{2} \mathrm{E}$ reencena o drama da criação, que tanto perpassa filhos e textos como o indivíduo que os gera e se gera através deles. Convém notar que a reincidência deste binómio, de livro para livro, também se pode ler como as entrelinhas de

\footnotetext{
${ }^{1}$ A vocação autoral frustrada de Brás Cubas em vida e a forma como (só) o romance póstumo dilui o patronímico Cubas através do nome de autor Brás Cubas é explorada no artigo "Mercúrio entrevado: Memórias póstumas de Brás Cubas em travessia" (FERREIRA, 2020), entre as páginas 84 e 86.

${ }^{2}$ Tendo conquistado espaço e preponderância relativamente a um cânone de ditames institucionais, $o$ indivíduo acabou por passar - auxiliado pelo realismo - de um eu ideal e inspirado a uma identidade crítica e expirante. Essa identidade veio a refletir-se na escolha coletiva de um nome como 'modernismo'. Faz lembrar certas expressões populares pejorativas acerca de autoimagens de grande importância, como "a última bolacha do pacote". Não se põe em causa a monta do modernismo nem a consciência que dela já então houvesse; quero apenas assinalar que a importância não se deve tanto à diferença entre as demais bolachas, mas ao facto de ser a última: estéril, mas fecundíssima. A questão da modernidade poderia comparar-se a um pacote de bolachas que começou a ser comido na antiguidade, hábito que se foi transmitindo ao longo das épocas. As subsequentes avaliavam o modo como anteriormente as bolachas eram comidas. Certas épocas imitavam a maneira de comer de umas e repudiavam a de outras. Os indivíduos do século XX herdaram o pacote e a sua história; e de tal forma que a escolha do nome indicia que queriam ser os últimos a comer a bolacha - o que é bem diferente de terem comido a última bolacha - e os primeiros a legar à posteridade um pacote vazio, na verdade cheio de migalhas das bolachas todas. A apropriação do atributo 'moderno' para a definição da índole, do tempo e do conjunto vanguardista de correntes artísticas do século XX é reveladora do impasse entre a consciência da efemeridade e o desejo de perpetuidade. Os que viessem depois seriam, quando muito, contemporâneos da importância do modernismo: a um passo a falta e o excesso de significado, e ainda a fantasia de um presente eterno - já não a última bolacha do pacote, mas migalhas. Bem se vê como poderia ter sido Quincas Borba a inventar o 'modernismo'.
} 
um romance de formação de Machado de Assis enquanto autor de romances; ou, melhor dizendo, enquanto autor de autores de romances. O problema da autoria agudiza-se nos romances da denominada segunda fase, inaugurada pela duplicidade de assinaturas do livro. $\mathrm{O}$ autor não se limitou à produção do que podemos estabelecer como criaturas - livros, enredos, personagens. Com as Memórias póstumas de Brás Cubas iniciava-se, como descreve Abel Barros Baptista, "o processo de diferenciação entre a assinatura nominal, que inscreve o nome de Machado, e a feição do livro, decidida por Brás Cubas" (BAPTISTA, 2003, p. 335). A chancela decisiva desse processo dá-se com o prólogo da terceira edição (ou quarta, consoante se considere a primeira publicação do romance na Revista Brasileira em 1880), em 1899 - o mesmo ano da terceira edição de Quincas Borba, com novo prólogo, e da primeira edição de $D$. Casmurro.

O nome Machado de Assis figurava na capa das Memórias desde a primeira edição, claro. O que o prólogo da terceira vem assumir e reclamar é o genitivo duplo: as memórias são do "meu Brás Cubas" (ASSIS, 2013, p. 15). A segunda fase instaura-se, em definitivo, nesse ponto de viragem paratextual: aí o nome Machado de Assis nasce oficialmente como pai de criaturas capazes de assinar, criadores de textos. Como afirma Baptista (2003, p. 336), o prólogo "exige as advertências posteriores para os romances anteriores": para aqueles que pertencem, como refere Machado na advertência da reedição do primeiro romance (Ressurreição, 1905), à "primeira fase" da sua "vida literária" (ASSIS, [2008 ou 2009]d). Se, por um lado, não renega em absoluto os romances da primeira fase, é certo que os põe no lugar: como se pode ler na advertência à reedição de Helena em 1905, a "feição" desses livros corresponde "ao capítulo da história do meu espírito, naquele ano de 1876" (ASSIS, [2008 ou 2009]b). Os efeitos retroativos das criaturas que sobrevivem ao criador de então, convertido em metáfora livresca, não são de desprezar. São homenageados parentes graças aos quais Machado de Assis pôde aperfeiçoar-se e alcançar uma fase de maturidade, e com os quais os laços são reconhecidos para que o corte, ou a diferença, seja mais evidente e laudatória. Relembra Abel Barros Baptista em Autobibliografias que o romance sobrevive "apenas através da exceção" que viola a sua lei:

[...] a anterioridade de um fundador é tão inescapável como é essencial a rejeição de um cânone ou corpo de prescrições que procure determinar os destinos do romance, ou seja, é tão necessário postular que o romance moderno se fundou, como defender que esse momento único da 
fundação depende da sua reafirmação repetida e incessante. (BAPTISTA, 2003, p. 316)

O esquema é afim ao de Said, mas a distinção entre filiação e afiliação torna-se aqui não irrelevante, mas redundante - em parte porque ambas resultam em esquemas idênticos e o emprego figurado de palavras como 'família', 'linhagem', 'dinastia' etc., é hoje recorrente: como diria Rorty (1989, p. 18), metáforas mortas. ${ }^{3}$ A ênfase incide na interdependência entre exceção e regra, na ruptura com a origem como condição de continuidade e na continuidade como possibilidade que deriva do reconhecimento da origem. Os termos filiação e afiliação interessam sobretudo de um ponto de vista técnico, graças à nuance que permite distinguir entre, por exemplo, natureza e cultura, autoria e apropriação, originalidade e legado, génese e adoção.

A advertência da primeira edição de Ressurreição (1872) é bem expressiva quanto ao posicionamento do jovem Machado: aprendiz esperançoso no próprio talento sob a supervisão de uma crítica justa. Retratase como romancista neófito mas leitor experiente, conhecedor "dos modelos". Uma vítima da literatura em vias de se tornar perpetradora, mas ainda e sobretudo uma vítima. Um "operário" disposto a subir a pulso, mas que por ora ainda responde perante a crítica, confiada à posição de patronato, a quem dá satisfações acerca do intuito do livro e termina pedindo "com o coração nas mãos" (ASSIS, [2008 ou 2009]d). Na advertência de $A$ mão e a luva(1874) paira ainda - mesmo considerando que a modéstia introdutória era um hábito autoral enraizado - a incerteza acerca do mérito da novela (ASSIS, [2008 ou 2009]a).

O autor revela, na advertênciaadvertência da reedição de Helena (1905), a estranheza que lhe causa a escrita do passado: "Agora mesmo, que há tanto me fui a outras e diferentes páginas, ouço um eco remoto ao ler estas, eco de mocidade e fé ingênua. É claro que, em nenhum caso, lhes tiraria a feição passada; cada obra pertence ao seu tempo" (ASSIS, [2008 ou 2009]b, grifo meu). Julgo que a fé a que se refere diz respeito à crítica, e ingénua porque volvidas três décadas Machado sabia, enfim, que tentar corresponder ao convencional se incompatibiliza com a disrupção que pode tornar o romance uma exceção prossecutora do género. E sabia que tirar aos romances a feição passada, substituindo-a pela atual, seria uma tarefa colossal e inglória, senão impossível.

\footnotetext{
${ }^{3}$ Rorty descreve o trajeto desde a criação à morte da metáfora: desde que provoca estranhamento até à completa acomodação na linguagem.
} 
A dúvida, que tematizara a advertência e o enredo do primeiro romance (1872), fora sendo metamorfoseada, ao decurso da primeira fase, na indeterminação estrutural que caracteriza a segunda. O par Esaú e Jacó e Memorial de Aires constitui o ponto em que essa indeterminação se manifesta no maior grau de maturidade e coerência. Aí podemos ver encenado, com a figura intermediária do Editor que se apropria dos escritos de um morto e transforma em romance o percurso errático da narrativa, o drama da reimpressão dos primeiros romances machadianos pelo Machado tardio.

Esaú e Jacó seria a última bolacha do pacote romanesco de Machado. Esteve mesmo em vias de se intitular "Último". Contudo, o escritor (porventura demasiado encaixotado pela crítica numa dualidade românticorealista, cuja preeminência sociológica tolhe evidentes traços de modernidade) deu com um pacote cheio de migalhas: nascia o Memorial de Aires. O tom da advertência tardia (1908) - escrita por um editor que se apropriava da narração mas recusava responder tanto pelo texto original como pelo sucedâneo publicado - é o oposto das advertências de 1872 e 1874, inclusive no que toca à crítica: não houve "nem pachorra, nem habilidade" de transformar a feição instável e truncada do diário numa forma repetida, familiar e determinada por capítulos (ASSIS, 2003, p. 8).

Considerando as afinidades entre as Memórias póstumas e Quincas Borba, Dom Casmurro é o romance da segunda fase machadiana que não tem um par. Dispensa advertência ou prólogo ou, se quisermos, ingerência paterna. O narrador constitui-se autor no primeiro capítulo, em que responde pela escolha do título e se mostra confiante de que acabará de escrever o livro. "Também não achei melhor título para a minha narração; se não tiver outro daqui até ao fim do livro, vai este mesmo" (ASSIS, 2008, p. 11). Não deixa de ser curioso que, segundo o narrador, o "livro" que já está a escrever só comece no terceiro capítulo. O segundo começa assim: "Agora que expliquei o título passo a escrever o livro. Antes disso, porém, digamos os motivos que me põem a pena na mão" (ASSIS, 2008, p. 12). A necessidade de vencer a monotonia de uma vida solitária parece secundarizar-se à medida que Bentinho descreve como encomendara, em outro local, a exata reprodução da sua antiga casa de infância - tempo e lugar remotos em que o livro começa, depois de abordar o início e fim da própria escritura.

Esse revivalismo compulsivo, que não logrou o "fim evidente" de "recompor o que foi" o passado e a pessoa - "mas falto eu mesmo, e esta lacuna é tudo" (ASSIS, 2008, p. 12) -, estende-se à reconstrução das memórias passadas: "Depois, pensei em fazer uma História dos subúrbios, [...] era obra modesta [...]. Foi então que os bustos pintados nas paredes entraram a falar- 
me e a dizer-me que, uma vez que eles não alcançavam reconstituir-me os tempos idos, pegasse da pena e contasse alguns" (ASSIS, 2008, p. 13). Ora, eis a última frase do livro: "Vamos à História dos Subúrbios" (ASSIS, 2008, p. 183). Melhor prova do falhanço da escrita em devolver Bentinho a Dom Casmurro, análogo ao da reprodução da casa, não se podia pedir. Resta apontar que os bustos que sugerem a escrita do livro (César, Augusto, Nero e Massinissa) são figuras não menos imponentes do que este motivo aparentemente modesto e acessório: "e assentarei a mão para alguma obra de maior tomo" (ASSIS, 2008, p. 13). A composição do livro seria, então, um modo acalentador de praticar a escrita com vista a escrever uma obra que não se limitasse a reconstituir a Bentinho um passado ideal - reidealizado ao ponto de a perda ser refeita como fruto da dissimulação de Capitu, e não da paranoia ou casmurrice do próprio narrador -, mas um livro, ainda que preliminarmente reconstitutivo (cf. capítulo II), como a história dos subúrbios, com uma destinação impessoal, pública.

Bento Santiago esquiva-se às formalidades preliminares em que o pai costuma intervir, mesmo que para afirmar que não pode prestar assistência ao filho, ${ }^{4}$ e começa a escrever um livro que simula o adiamento do próprio início através da fantasia camuflada de um sucessor. Assim, e embora não tenha um par material, Dom Casmurro apresenta ao leitor a possibilidade en abyme de um livro que o supere, na condição de que o próprio Dom Casmurro seja escrito e preliminar.

Quincas Borba é, de certo modo, a concretização en abyme de uma possibilidade autoral criada nas Memórias póstumas, a do filósofo. $\mathrm{Na}$ primeira versão do romance, publicada n'A Estação, a ordem cronológica da narrativa torna mais evidente que o espólio legado pelas Memórias é como a moldura de um abismo em que os mais frágeis e volúveis vão caindo. É logo no primeiro capítulo que o narrador de Quincas Borba se apropria da autoria das Memórias:

Aqui, toda a gente que me fez o favor de ler as Memórias póstumas de Brás Cubas, lembra-se [...] de que aparece ali, em três ou quatro capítulos, um tal Quincas Borba, e pergunta e cuida naturalmente que é o mesmo. Cuida bem. Mas não é preciso ler as Memórias; basta saber que é o mesmo, e que vai morrer, como disse o médico. Pode ir, que não precisamos dele. Que fosse criança graciosa, mendigo algum tempo,

\footnotetext{
${ }^{4}$ Referência não apenas à prática prefacial, mas também a uma das quatro características pelas quais Sócrates considera que o discurso escrito é inferior ao discurso vivo e animado: "maltratado e insultado injustamente, necessita sempre da ajuda do seu autor". Cf. Platão (2009, 275e, p. 122).
} 
herdeiro inopinado e inventor de uma filosofia, não temos nada com isso. Quando muito, é bom saber (e aqui lho digo) que alguns anos antes, um médico supôs que este Quincas Borba tinha um grãozinho de sandice, cousa de nada (está no cap. CLIII das Memórias), é bom sabê-lo para explicar algumas disposições testamentárias do homem, que vai morrer daqui a pouco.

Repito que não precisamos dele, [...] só precisamos do nome do homem, e não pelo homem, senão pelo cão, [...] que o nome era comum ao cachorro e ao dono. (ASSIS, [2008 ou 2009]c)

Na versão publicada em livro, o cotejo entre os dois romances é francamente truncado, reduzido a uma frase no capítulo IV:

Este Quincas Borba, se acaso me fizeste o favor de ler as Memórias póstumas de Brás Cubas, é aquele mesmo náufrago da existência, que ali aparece, mendigo, herdeiro inopinado, e inventor de uma filosofia. Aqui o tens agora em Barbacena. [...] Saberia Rubião que o nosso Quincas Borba trazia aquele grãozinho de sandice, que um médico supôs acharlhe? (ASSIS, 2012, p. 50)

A independência de Quincas Borba em relação ao romance anterior deixa de ser iterada pelo narrador, mas passa a ser reiterada e assinada por Machado no prólogo da segunda edição (1896), antes do prólogo das Memórias (1899):

Já na primeira edição se disse (capítulo IV) que o título do livro é o nome de um personagem que aparece nas Memórias póstumas de Brás Cubas. Se lestes os dois livros, sabeis que é o único vínculo entre eles, salvo a forma, e ainda assim a forma difere no sentido de ser aqui mais compacta a narração. (ASSIS, 2012, p. 43)

Machado tentou prestar assistência ao filho mais novo, afirmando a sua constituição, em pleno direito, enquanto criatura independente da anterior. Embora assine o prólogo em nome próprio, tem o cuidado de preservar a distância relativamente ao narrador: não afirma que "já na primeira edição (eu) disse", e sim que "já na primeira edição se disse". Quincas Borba também constitui uma exceção na segunda fase machadiana, na medida em que não participa da estratégia filial do autor inventado, mas não pode desvincular-se inteiramente da forma inaugurada com as Memórias póstumas. Desde a versão folhetinesca observa-se, então, a gradação entre 1) a desvalorização inicial da leitura das Memórias e reiteração da pequenez e inutilidade do 
filósofo porque "só precisamos do nome do homem" (ASSIS, [2008 ou 2009]c), 2) a truncagem drástica desse parágrafo simultaneamente vinculatório e apropriatório e a sua deslocação do capítulo I para o capítulo IV e 3) o prólogo da segunda edição em que Machado afirma que "o título do livro é o nome de um personagem que aparece nas Memórias póstumas de Brás Cubas" (ASSIS, 2012, p. 43, grifo meu).

O prólogo da terceira edição (1899) refere e rejeita a sugestão de um amigo, a de fazer "uma trilogia" em que "a Sofia de Quincas Borba ocupará exclusivamente a terceira parte". Machado diz ter considerado a hipótese, mas depois de reler o romance conclui que não: "A Sofia está aqui toda. Continuá-la seria repeti-la, e acaso repetir o mesmo seria pecado" (ASSIS, 2012, p. 45). Podemos deduzir algumas coisas:

a) Considerar a hipótese da trilogia implica reconhecer o vínculo entre as Memórias póstumas e Quincas Borba, quiçá além da forma.

b) Considerar que "repetir o mesmo seria pecado" implica reconhecer, e de forma mais categórica do que no prólogo anterior, ainda que implícita, que esse vínculo é inovador.

c) A eliminação da hipótese de Sofia se tornar vínculo entre Quincas Borba e um romance subsequente porque já está "toda" escrita obriganos a deduzir que Quincas Borba não estava todo nas Memórias.

O que leva Sofia a estar toda em Quincas Borba e Quincas Borba a não estar todo nas Memórias póstumas são questões que este ensaio aflora mas não elabora. Ambos os personagens são, tanto quanto sabemos, "órfãos às avessas", mas só um deles tentou ou quis tornar o seu nome a extensão de uma obra. Não é por acaso que à representação clássica do autor corresponde, à imagem do deus patriarcal, a figura do pai; metáfora morta - prova de que os mortos têm a sua utilidade - e avantesma do banimento da voz feminina ao longo de séculos, modernismo inclusive. O caso de 'Sofia' ser um nome estéril do ponto de vista autoral e de isso provavelmente ter constituído um fator de exclusão é representativo não apenas da marginalização da autoria feminina, mas da própria preponderância que a geração de autores tinha para Machado de Assis. Em toda a segunda fase romanesca machadiana podemos e devemos considerar a hipótese do nome enquanto personagem. ${ }^{5} \mathrm{E}$ de, em Quincas Borba, o nome próprio ser a grande personagem do livro - como um pacote de bolachas esvaziado e deixado à sorte dos sucessores.

\footnotetext{
${ }^{5}$ Abel Barros Baptista (2003, p. 331), no posfácio às Memórias póstumas de Brás Cubas, toca numa ideia aparentada: a de que "o livro é realmente escrito pelo nome de Brás Cubas".
} 


\section{Referências}

ASSIS, Machado de. Memorial de Aires. Lisboa: Edições Cotovia, 2003.

Dom Casmurro e Esaú e Jacó. Lisboa: Relógio D'Água Editores, 2008.

. A mão e a luva. Rio de Janeiro: Fundação Casa de Rui Barbosa: CNPq: Faperj,

[2008 ou 2009]a. Disponivel em:

<http://machadodeassis.net/hiperTx_romances/obras/amaoealuva.htm>. Acesso em: 31 out. 2021.

Helena. Rio de Janeiro: Fundação Casa de Rui Barbosa: CNPq: Faperj, [2008 ou 2009]b. Disponível em: <http://machadodeassis.net/hiperTx_romances/obras/helena.htm>. Acesso em: 31 out. 2021.

. Quincas Borba - A Estação. Rio de Janeiro: Fundação Casa de Rui Barbosa: CNPq:

Faperj, [2008 ou 2009]c. Disponível em: <machadodeassis.net/hiperTx_romances/obras/quincasborbaaestacao.htm>. Acesso em: 31 out. 2021.

. Ressurreição. Rio de Janeiro: Fundação Casa de Rui Barbosa: CNPq: Faperj, [2008

ou 2009]d. Disponível em:

<http://machadodeassis.net/hiperTx_romances/obras/ressurreicao.htm>. Acesso em: 31 out. 2021.

Quincas Borba. São Paulo: Penguin Classics Companhia das Letras, 2012.

. Memórias póstumas de Brás Cubas. Lisboa: Edições Cotovia, 2013. (Curso breve

de literatura brasileira, v.1).

BAPTISTA, Abel Barros. Autobibliografias: solicitação do livro na ficção de Machado de Assis. Campinas: Editora da Unicamp, 2003.

FERREIRA, Diana Duarte. Mercúrio entrevado: Memórias póstumas de Brás Cubas em travessia. Machado de Assis em Linha, São Paulo, v. 13, n. 31, p. 77-92, 2020. Disponível em:

<https://www.scielo.br/j/mael/a/JsMQGf8V7kFLsxkbDyDMfxt/?format=pdf\&lang=pt>. Acesso em: 31 out. 2021. doi: 10.1590/1983-6821202013315.

PLATÃO. Fedro. Trad. José Ribeiro Ferreira. Lisboa: Edições 70, 2009.

RORTY, Richard. The Contingency of Language. In: Contingency, Irony and Solidarity. Cambridge, UK: Cambridge University Press, 1989.

SAID, Edward W. The World, the Text, and the Critic. Cambridge, Massachusetts: Harvard University Press, 1983. 
Machado de Assis em Linha - Universidade de São Paulo

http://machadodeassis.fflch.usp.br - Artigo

DIANA DUARTE FERREIRA é doutoranda em Estudos Portugueses na Faculdade de Ciências Sociais e Humanas da Universidade Nova de Lisboa e licenciada em Estudos Portugueses pela mesma instituição. Tem desenvolvido as suas pesquisas em torno de literatura brasileira, teoria da literatura e estudos interartes. É desde 2021 bolseira de investigação para doutoramento do IELT/FCT com um projeto de investigação em torno da obra de João Guimarães Rosa. Tem dois artigos publicados na Machado de Assis em Linha e um artigo sobre o livro Bandolim de Adília Lopes na Journal of Lusophone Studies.

Orcid: https://orcid.org/0000-0002-7554-2715. E-mail: diana.duart@icloud.com

Recebido: 02.11.2021

Aprovado: 16.11.2021 